\title{
The Function of volunteer organizations in public crisis management: from the perspective of transaction cost
}

\author{
HAIYAN WANG \\ School of economics and management \\ Huashang College, Guangdong University of Finance and Economic \\ No. 1 Zengcheng Avenue, Zengcheng District, Guangzhou \\ CHINA
}

\begin{abstract}
In the fight against the COVID-19 in China, many volunteer organizations emerge, which are both efficient and flexible in some situations. To summarize the experience of these organizations in public crisis management, this paper divides the work situations faced by organizations into conventional situations and unconventional circumstances and to compare the functions of formal and informal organizations in conventional and unconventional circumstances from the perspective of transaction cost and analysis factors which influence their cooperation in public crisis management. By examining the functions of NCP in the fight against the COVID-19, this research proposes that transaction cost is a critical factor to consider in the function and structure of informal organizations. Thus, this paper suggests that in the governance of public crisis, the government should incorporate informal organizations into the social governance system and focus on their organizational advantages. It is essential to classify social organizations, innovate the management mode of social organizations, and elucidate the correlation between vertical government governance and horizontal
\end{abstract}

social governance, changing the "inverted T" operation mode into the "cobweb" cooperation mode

Keywords:- the function of volunteer organization; public crisis management; transaction cost;

Received: June 1, 2020. Revised: December 19, 2020. Accepted: January 4, 2021. Published: January 15, 2021

\section{Introduction}

The traditional idea is that the government is responsible for public crisis governance. However, in the post-pandemic era, public crisis management displays the characteristics of normalization, which inevitably proposes new requirements for the existing social governance system and governance capacity. The new scenario needs the government to execute extensive cooperation with the private sector and nongovernmental organizations, constructing a diversified and flexible cooperative model of governance and effectively handling complex and uncertain social problems [1]. Numerous volunteer organizations, such as NCP and Beijing-Hubei "I will" action, the big fish CAN project, DaBie Mountain Youth League, love motorcade, and temporary mask production organization initiated by Jiangsu entrepreneurs, are nongovernmental informal organizations established by volunteers that act on their own initiative. In the fight against the pandemic, such organizations quickly organized social forces to participate and respond to social needs, thereby effectively alleviating the government's lag and blank in the response of crisis. Consequently, they have become an integral force in crisis management. Lately, the public crisis has markedly stimulated nongovernmental forces to participate in social governance. Around a significant number of nongovernmental organizations have been established spontaneously in the current pandemic. The following are standard features of these organizations: (i) committed to resolving social issues arising from the public crisis; (ii) primary reliance on social forces to engage in social public welfare services; (iii) members are scattered all over the country at ordinary times but converge with a sense of public interest when needed; and (iv) most are not officially registered and are in an organizational form between unorganized and formal organizations, which we term as "informal organizations" in this study. Compared with formal organizations represented by government organizations, informal organizations are more flexible and efficient in public crisis governance; however, these are usually short-lived. To familiarize with these organizations and summarize the experience of social governance, we must answer the following questions: What are the functions of volunteer organizations in public crisis governance? How can these organizations play an influential role in crisis management? 


\section{Literature Review and Analysis Framework \\ 2.1Literature review on public crisis management}

In 1986, Beck (2004), a German sociologist, posited the theory of risk society. He believed that modernity and risk coexist, and that crisis governance is one of the crucial contents of modern governance[2]. Essentially, the governance logic in post-industrial society and industrial society is markedly different. To decrease uncertainty and evade risk, the industrial society has recognized the division of labor, and the government and enterprises have established hierarchical organizations to minimize risks and costs levied by their transactions. Becker contended that the industrial society, which aims to decrease the uncertainty, has posed a series of social risks, rendering the modernization process "reflexive." To manage social risks and crises, it is imperative to break the division of labor and organizational boundaries, and foster the connection and collaboration between organizations and departments.

The existing literature worldwide revealed that crisis governance warrants cooperation across domains, organizations, and sectors, and the central problem is how to divide and coordinate between multi-agents. Zhang and Leng proposed to build the collaborative governance mechanism from the synergic theory [3,4,5]; Liu and Xiang proposed that the government is the main body and the central government is the highest and unified decisionmaking body, government agencies should routinely and systemically actively cooperate with nongovernmental organizations, enterprise groups, individual citizens and international organizations [6]; Guo and Zhu proposed the cross-domain crisis holistic governance mechanism to solve the problem of "fragmentation" in crisis governance cognition, resource and power distribution, policy formulation and implementation [7]; Sun and Liu proposed the non-governmental organizations are the main mechanism of mobilizing people to help themselves [8]; Zhang proposed the concept of fuzzy governance which is elastic, differentiated and inclusive[9]. All studies mentioned above recognized the problems in the current system, such as fragmentation, compound governance levels, and multi-party command, and recommended the adoption of the law to demolish the administrative and geographical boundaries, build institutional trust, and complete the transformation from the conventional division of labor governance to collaborative governance in crisis governance. Furthermore, public crisis governance needs to manage not only technical problems but also reform and innovate the social governance structure.

Although the prevalent theories offer an analytical framework and cognitive path for China's social governance innovation, the problem is that the majority of the theoretical derivation remains tell us what to do [10]. But, there is little study tells us why. Thus, this study aims to explore the structure, function of informal organizations from the standpoint of transaction cost theory.

\subsection{Transaction cost theory on organizational structure and function}

Ronald Coase formally founded the transaction cost theory, which illustrates the reason of economic organizations' emergence when the market can assign resources; alternatively, it can be rephrased as what is the boundary of enterprises and why there are enterprises? Coase (1937) pointed that economic organizations are established because of the cost of market allocation of resources. The limited rationality and opportunism of market subjects caused transaction costs like information asymmetry and moral hazard[11]. In addition, transforming market transactions into internal transactions through economic organizations can decrease uncertainty and transaction costs. Williamson (2016) further investigated the transaction contract systematically, claiming that the blend of contract and corresponding governance structure can efficiently decrease the transaction cost, which, in turn, depends on the asset specificity, transaction uncertainty, and transaction frequency. the purpose of organization is to permit the realization of the distinctive advantages of both small and large firms which apply at different stages of the innovation process. [12,13]. Cheung equated transaction cost with an institutional cost and reported that the change of transaction cost would result in the change of contract structure or organizational structure, and transaction cost could be decreased through institutional rearrangement [14]. Likewise, political institutions are driven by the motivation to decrease transaction costs. Zhang argued that the benefits of the political system lie in the shared interests of all agencies that can be reached in the transaction owing to the low cost of economic action and open process of accomplishing the goal. Hence, it is easier to predict and regulate the change of the political process by decreasing the opportunism and uncertainty. Furthermore, the political system confines the absolute freedom of individuals and groups; however, it creates the order 
and stability of the political process, which enhances the total social income and efficiency [15].

A brief review of the transaction cost theory revealed that the theory explicates that the market transaction risk can be efficiently decreased through the form of organization. Of note, the mechanism lies in the connection between organizational structure and transaction cost; however, the connection remains unclear, and the difference primarily depends on the task situation (i.e., institutional environment) that the organization faces (refer table for details).

\subsection{Analysis Framework}

Based on the transaction cost theory, we divided the task situations encountered by organizations into two types: conventional situations and unconventional situations (Table 1). While the conventional situation denotes the institutional environment with definite work, clear task, and high transaction frequency, the unconventional situation implies the institutional environment full of uncertainty with task uncertainty, short-term, or disposable work. Comparatively, when formal organizations encounter conventional circumstances, transaction costs can be decreased, and the efficacy of operational and resource allocation can be enhanced because of the specialized division of labor structure of hierarchical organizations. In the face of unconventional circumstances, informal organizations have an advantage because of their flat and flexible organizational structure, which can be easily adjusted. Thus, transaction costs can be decreased. Conversely, when formal organizations face unconventional circumstances or informal organizations face conventional circumstances, both experience problems of high transaction cost and low operation efficiency owing to the mismatch between the task and the organizational structure.

In public crisis management, working situations can be distinguished into conventional situations and unconventional situations. Conventional situations are with high certainty, clear task, and strong repeatability, such as virus detection in epidemic situations, administration of community and personnel, public donation, and disposition of medical materials, which are finished by the government and formal public welfare organizations with low transaction costs. Meanwhile, there exist significant unconventional situations with high uncertainty, such as sudden community epidemic, shortage of medical and living materials, and mass panic, which warrant a response in the short term. Informal organizations have more benefits in managing unconventional tasks with lower transaction costs and higher efficiency owing to the flexibility of organizational scale and flexible internal division of labor and resource allocation.

Thus, in the fight against the new pandemic situation, many informal public welfare organizations cropped up, which timely supplemented the work that the government and formal organizations could not handle alone, thereby developing a complementary and coordinated anti-epidemic mode

Table 1: The structure and transaction cost of different organizations in different task situations

\begin{tabular}{|l|l|l|}
\hline $\begin{array}{l}\text { Organization } \\
\text { structure }\end{array}$ & $\begin{array}{l}\text { Formal } \\
\text { organization } \\
\text { (with } \\
\text { bureaucratic } \\
\text { organization, } \\
\text { large and fixed } \\
\text { scale, long- } \\
\text { term } \\
\text { operation, } \\
\text { clear internal } \\
\text { division of } \\
\text { labor) }\end{array}$ & $\begin{array}{l}\text { Informal } \\
\text { organization } \\
\text { voluntary } \\
\text { organization, } \\
\text { irregular scale, } \\
\text { short-term } \\
\text { operation, } \\
\text { flexible division } \\
\text { situation labor) }\end{array}$ \\
$\begin{array}{l}\text { Conventional } \\
\text { situation } \\
\text { (with low } \\
\text { uncertainty, } \\
\text { clear task, and } \\
\text { high } \\
\text { transaction } \\
\text { frequency) }\end{array}$ & $\begin{array}{l}\text { Low costs, } \\
\text { specialization, } \\
\text { high } \\
\text { operational } \\
\text { efficiency, and } \\
\text { normalize } \\
\text { resource } \\
\text { allocation }\end{array}$ & $\begin{array}{l}\text { High transaction } \\
\text { costs, } \\
\text { professional } \\
\text { division of labor, } \\
\text { high operating } \\
\text { costs }\end{array}$ \\
\hline $\begin{array}{l}\text { Unconvention } \\
\text { al situation } \\
\text { (with high } \\
\text { uncertainty, } \\
\text { uncertain task, } \\
\text { low } \\
\text { transaction } \\
\text { frequency) }\end{array}$ & $\begin{array}{l}\text { High } \\
\text { transaction } \\
\text { costs, low } \\
\text { operational } \\
\text { efficiency, and } \\
\text { resource } \\
\text { allocation }\end{array}$ & $\begin{array}{l}\text { Low operation } \\
\text { cost; Flexible } \\
\text { resource } \\
\text { mobilization and } \\
\text { resource } \\
\text { allocation }\end{array}$ \\
\hline
\end{tabular}

\section{The Difference and Combination of Formal and Informal Organizations in Public Crisis Governance}

Table 1 demonstrates the correlation between different organizational structures and transaction costs in different task situations, showing that although in the public crisis governance, the organizations might still encounter diverse task situations (institutional environment). Thus, making different organizational structure choices is imperative. Some public goods are global and homogeneous, which are categorized as pure public 
goods, whereas others have local and private externalities, which are categorized into quasipublic goods[16]; both types of public goods with significant differences have different matching requirements for organizations. Moreover, the differentiated organizational structure creates different transaction costs and decides the operational efficiency of organizations.

\subsection{Comparison of structure function and transaction cost between formal and informal organizations}

Based on the empirical facts, both formal organizations (i.e., government) and informal organizations (i.e., informal volunteer organizations) have their own merits and demerits. As the saying "there is no bureaucratic system that is in charge of small matters. The people need to organize themselves to solve various contradictions among the people. The "bureaucratic system" is an organization that does big things and can't do small things; only "flat organizations" can do small things.[17] More specifically, from Figure 1(a), the government has a advantage in providing public goods with the character of mass and single, high asset specificity and high transaction frequency with high certainty and low cost, because the government has the vertical bureaucratic system and perfect management system from the central to the local that can guarantee the timely supply of public goods with high efficiency. From Figure 1(b), informal volunteer organizations, on the other hand, have the advantage of providing public goods with high uncertainty, low transaction frequency, a small number of complicated steps, and low asset specificity with low cost because informal organizations have a flat structure, flexible scale, flexible response, and voluntary participation, which are appropriate for a small batch and multi-type anti-pandemic needs of the community. From the perspective of transaction cost, each type of organizational structure has its own advantage at providing specific public goods.

Figure 1: The different transaction cost between Formal and Informal transaction cost in Public Crisis Governance

Figure 1(a): the transaction cost of Formal transaction cost

Figure 1(b): the transaction cost of Iinformal transaction cost

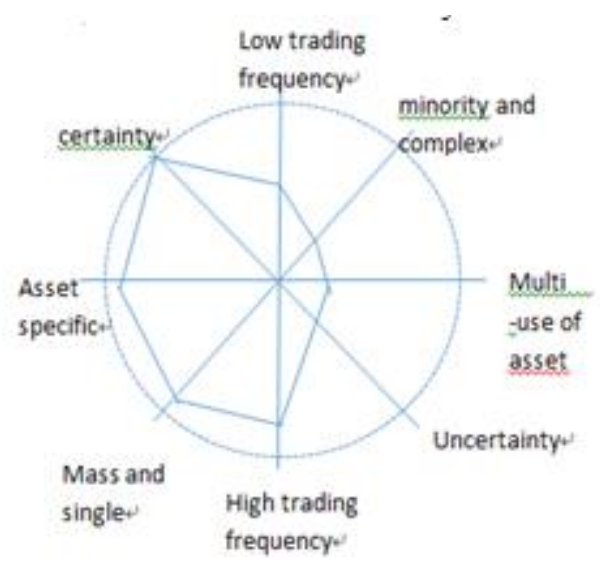

a-the transaction cost of Formal organizations

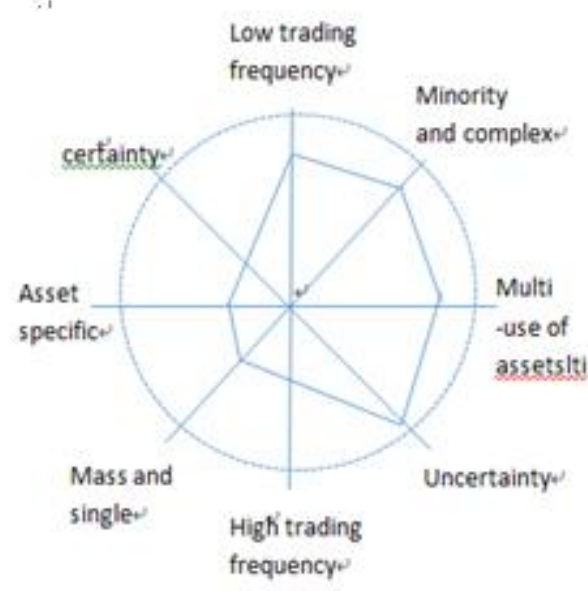

b: the transaction cost of Informal organizations

\subsection{Social welfare when formal and informal organizations conjointly provide public goods}

The extent of social welfare obtained by combining public goods provided by formal and informal organizations conjointly is a question worth exploring. As shown in Figure 2, suppose, in the public crisis governance, the social welfare provided by the government for public goods is $A+C$, the social welfare provided by nongovernmental organizations is $B+C$, and $C$ is the intersection of public goods provided by the government and nongovernmental public welfare organizations, that is, the field of shared services. If the functions of government and informal organizations are wellmatched and harmonizing, the total social welfare attained by the combination of the two is $A+B+C$, thereby increasing the total social welfare. Conversely, if the government and nongovernmental informal organizations are 
mismatched, or even antagonistic to each other (e.g., the government wants to ban nongovernmental informal organizations, and nongovernmental informal organizations decline cooperation with the government), a mismatch of resources and mutual cancellation might exist. In such a case, the total social welfare attained is $A+B$, compared with the former, the latter has evident welfare loss $(C)$. To evade the welfare loss, the communication, information communication, and collaboration between the government and informal organizations must be strengthened; this warrants not only a reasonable division of labor in the vertical and horizontal governance systems and the fortitude of their behavioral boundaries but also synchronization and interaction in mechanism and policy to complement each other.

Figure 2: The Social welfare of Formal and Informal Organizations in conjointly providing public goods

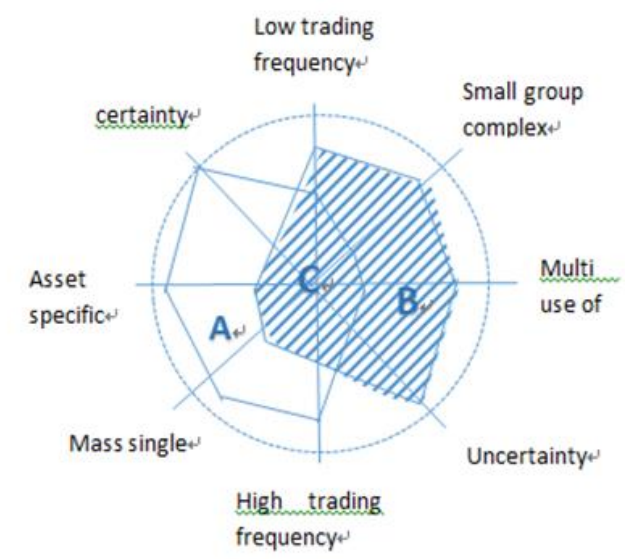

\section{Analysis of Typical Cases of Informal Organizations Participating in Public Crisis Management}

The novel coronavirus pandemic posed humanity a challenge in the form of a global public crisis. To date, China's novel coronavirus pneumonia is the most severe public emergency that has spread fastest, becoming the most widely spread and the most problematic to control since the founding of new China. The novel coronavirus pneumonia not only created a public health crisis and threatened human health and life but also led the government and public to encounter composite and unpredictable circumstances, causing public panic and social order, as well as becoming a complex of a public health crisis, economic crisis, and social crisis. Currently, the virus has been effectively suppressed in China, and China's experience lies in both the government and social organizations have played an active role.

The new crown life support network (NCP; initiated by Hao Nan, a professional public-spirited person who was a dentist before becoming a public welfare person) is a volunteer organization established spontaneously in the early stage of the pandemic in China. At the beginning of the pandemic, owing to the scarcity of medical resources in Wuhan, Hao Nan made a decision based on his experience of public-spirited people and doctors. He decided to conduct hierarchical diagnosis and treatment, open up online clinics to offer services for mild patients and isolated people in Wuhan, and leave scarce medical resources to severely ill patients. He immediately joined a group of doctors and volunteers with the same ideals to cooperatively organize and establish NCP, which today has become a major nongovernmental force to support new crown patients and their families.

NCP built a team in only 1 day. NCP selected 400 professional medical workers from over 2000 volunteers who consented to participate and built three main groups - online diagnosis and treatment, consulting service, and psychological care service. When the government's allocation of medical resources was out of place, NCP's hierarchical diagnosis and treatment system received over 5000 patients, among them, more than 2000 were severe cases, probably accounting for about $1 / 10$ of the total severe patients in Wuhan at that time. NCP pacified the anxiety of patients, and gathered social support. After the follow-up of government medical resources, NCP timely shifted to the task of online psychological counseling and post-disaster reconstruction.

NCP effectively made up for the lag of the government in the resource allocation in the early stage of the new epidemic. In the later stage, after the allocation of government resources was in place, it quickly adjusted its own positioning, reflecting the characteristics of efficient, flexibility and innovation. NCP managed to create a team in record time, which can be attributable to its organizational flat structure. The structure is feasible at the unconventional situations. On the other hand, the strategy of reducing transaction cost of NGO also leads to the flattening of organizational structure. In this case, the low transaction costs lies in its "informal" identity.

The transaction cost of NCP is low compared with the formal organization.

First, the formal organizations need to register. Generally speaking, a formal NGO need look for a professional authority. Then through fund raising, 
team building, registration, a formal NGO is born. The process needs not only time, but also the fund. The NCP is informal, which means it is without registration. Why does it not register? Unconventional tasks make it impossible for them to register. Hao Nan said, "we are paying attention to the changes in the epidemic situation and dealing with new problems every day. There is no one who has the time to consider the registration." NPC chose to put limited resources into crisis management.

Second, the formal organizations have organizational institution, organizational structure and fixed human resources which can be seen as the operating costs. The informal organizations take problem-solving as the goal and volunteers as the core resources, and replace supervision and system with trust and common ideas. Such a governance structure effectively reduces operating costs. NCP provides the diagnosis and treatment services by a group of medical volunteers. It's flat organizational structure make it efficient and innovative. Hao Nan said that NCP "needs to pay attention to the development of the epidemic situation and update the process every day. The core members can only sleep for two or three hours a day who have no pay." Initially, NCP was established to serve patients with mild illness; however, later, severe patients also turned up for a consultation, causing them to adjust the diagnosis and treatment plan urgently. In Hao Nan's words, “At the begin, they didn't want to do the ventilator project and oxygen generator project. At that time, the organization was initiated temporarily." Hence, it can be deduced that efficiency and innovation benefit from the open and flat organizational structure of informal organizations.

Third, the organization's internal governance primarily relies on the strength of social capital, which considers the value identification, trust and, reciprocity among organizational members as a form. Coleman (1990) claimed that voluntary association is one of the leading forms of social capital[18], whereas Putnan, Leonardi and Nanetti (1994) directly equated voluntary community with total social capital[19]. Notably, social capital can efficiently decrease the cost of organization and management synchronization and augment the work efficiency of the organization, which is the inherent advantage of public welfare organizations.

In addition, NCP encountered issues in the implementation. First, in the absence of any registration, no government department considered supporting such an organization. Thus, the communication channels between them and the government were not smooth, and they could not gather recognition and funding. In such a scenario, they could only turn to seek social support. NCP gained two donations from other social organizations to cover its operating costs. Second, the material acceptance channel was not smooth. NCP and other social organizations collaborated on ventilator and oxygen-generator projects, as well as encountered difficulties in the process of material docking with victims. Hao Nan said, "There is no hub-type social organizations or related government organizations at all levels to communicate the needs of society and the donation and materials from all walks of life and does the implementation. The asymmetry of demand and information has resulted in improper matching and repeated allocation of resources." Clearly, there existed an information block between local demand and support agencies, which reflects several persistent problems in the collaboration between vertical and horizontal governance systems. So, the social welfare is $A+B$, but not $A+B+C$. as shown in Figure2.

\section{Policy Recommendations \\ 5.1First, innovate social governance.}

In 1995, the Global Governance Committee published a research report entitled "Our global partnership," which clarified the characteristics of governance. Governance is the sum of multiple ways in which public or private individuals and institutions handle their public affairs. In addition, governance is an ongoing process of reconciling conflicting or dissimilar interests and taking shared action. Besides, it includes not only formal institutional arrangements and rules that compel people to obey but also multiple informal institutional arrangements that people agree or think are consistent with their interests (Commission on Global Governance, 1995)[20]. The essence of governance lies in the participation of individuals or social organizations in resolving mutual social problems. Public crisis often kindles people's motivation to participate in social governance, and informal organizations serve as the platform for people to do so. The analysis of transaction cost revealed a correlation between different transaction costs and organizational structure; there is not only one form of organizational structure. And in the unconventional situations, the informal organizations have the advantage of high efficiency and flexibility. Thus, the government should offer policy support to the innovation of social organizations, inspire social organizations to 
examine organizational forms suitable for their own objectives and conditions, and suitable management and supervision system. Conversely, if "one size fits all" conventional organizational management is followed, the operation of nongovernmental informal organizations inevitably produces higher transaction costs, which would decrease their organizational efficiency or render them to remain in an informal legal state. Hence, we suggest that for such organizations, the government could adopt a short-term (1-2 years) registration and filing system to decrease transaction costs, bestow organizations with legitimacy, enable internal management and external cooperation, and create more social welfare.

5.2 Smooth out the correlation between the vertical governance system and the horizontal governance system, and modify the "inverted $T$ " cooperation mode into the "cobweb" cooperation mode.

The key to social management innovation lies in how to manage the effective connection between vertical integration and horizontal coordination mechanism, that is, how to endorse public participation and create effective social consultation to kindle the internal vitality of the society and reinforce the vertical order to attain effective social integration [10]. The premise of encouraging public participation in social governance is to endorse the innovation of social organization form. As mentioned earlier, loose regulatory policies should be adopted to reassure the development of social organizations to accommodate more people to participate in social governance and accomplish effective social consultation. Thus, the government should not only support social governance innovation but also simplify the laws and regulations of public participation. For instance, in public crisis governance, no relevant provisions exist on how to collect government funding for disaster relief services because previous disaster relief activities were restricted to donations. However, today, a growing number of organizations offering various disaster relief services have played a vital role in crisis management. The lack of policies makes it challenging for such social organizations to attain social support. Indeed, the lag of policy-making is that such organizations are not registered, and the "flash in the pan" strategy makes it problematic for their voices and demands to be delivered to government departments; besides, barriers still exist between vertical and horizontal governance systems. Notably, public participation is limited to the bottom, the government and society exhibit an "inverted $T$ " cooperation mode, and public participation cannot leap forward the grassroots level. During crisis management, the channel between social organizations and people being rescued is not entirely unclogged, and there exists a lack of information communication channel between the need for relief and social supply, which would easily cause problems of asymmetric supply and demand and repetitive allocation of resources. The vertical governance system and horizontal governance system should develop a "cobweb" cooperation mode and progressively investigate the construction of multi-agent co-governance pattern at the level of villages and residences. Furthermore, the forms and ways should include improving laws and regulations, creating a provisional working mechanism, purchasing public services, and outsourcing projects. Only by establishing effective communication between vertical governance mechanism and horizontal governance mechanism can social welfare be increased from $A+B$ to $A$ $+B+C$, as shown in Figure2.

\section{Conclusions and Enlightenment}

In public crisis governance, any single subject cannot undertake the governance task of the entire society. As society is an extensive system built by the interaction of multiple stakeholders, the efficiency of social governance is multifaceted and comprehensive, and no optimal single governance method and governance structure exist, especially in the field of the public health crisis that is full of uncertainty[21].

Taking the participation of informal public welfare organization NCP in COVID-19 as an example, this study demonstrates that in some distinct areas and particular periods of social life, people can instinctively create social organizations to assist each other and resolve challenges together. As the saying "there is no bureaucratic system that is in charge of small matters. The people need to organize themselves to solve various contradictions among the people. The "bureaucratic system" is an organization that does big things and can't do small things; only "flat organizations" can do small things. In the period of public crisis, or in the unconventional situations, the advent of mass selforganizations demonstrates that civil society is becoming mature. In contrast, even if the organizational power in the system is strong, it cannot catch the dead corner, which must be filled by nongovernmental organizations. To grasp the maximization of social welfare, the government and social organizations must perform their respective duties, give full play to their respective advantages, and reach effective collaboration based on the social 
division of labor. In addition, this study claims that the transaction cost theory is an operative tool to illustrate the selection of organizational structure and behavioral strategy in the field of social governance. While constructing the social collaborative governance mechanism, the government, as the leading force, should provide policy support and legal recognition to the institutional innovation of several social organizations, actively dredge the collaboration channels between the government system and the social system, and alter the "inverted T" cooperation mode to the "cobweb" cooperation mode to materialize the reconstruction of social structure and augmentation of public welfare.

\section{References:}

[1] Zhang.K. Towards cooperative society ,Beijing: China Renmin University Press, 2015: pp .112-115

[2] Beck U. Risk society, Beijing. Yilin publishing house, 2004: pp .91-130.

[3] Zhang L., \&Leng, X. Discussion on the innovation of public crisis management mode in the context of synergetics, China Administration, No 10,2007,pp.100-104.

[4] Zhang L.,\& Leng X. Collaborative governance and innovation of public crisis management model in China: Based on the perspective of synergy theory, Journal of central China Normal University (HUMANITIES AND SOCIAL SCIENCES), Vol 47 No 2, 2008,pp.11-19.

[5] Sha,Y., \& Xie Z., On collaborative governance of public crisis, China Administration, No. 4, 2010,pp.73-77.

[6] Liu X.,\& Xiang L. Network governance structure: the realistic choice of China's public crisis decision-making system, Social science, No.004, 2005, pp.34-39.

[7] Guo X.., \& Zhu,Z. Research on organizational coordination in Holistic Governance of cross domain crisis: Based on the perspective of Inter Organizational Network, Journal of public management, Vol 8 ,No4, 2011,pp. 50-60.

[8] Sun, X.., \&Liu T. Functional boundary and optimization strategy of social mobilization in public crisis management, Journal of Wuhan University: Philosophy \& Social Sciences, 2020 No.3,pp.23-32.

[9] Zhang, L. Fuzzy management in epidemic Management: Governance Logic of uncertainty risk ,Journal of Beijing University of science and Technology (SOCIAL SCIENCE EDITION), Vol. 2, 2020,pp. 36.

[10] Li, Y. Problems encountered in the new pattern of social management in China: A Perspective
Based on the analysis of meso mechanism, Academic monthly, No.7, 2012,pp. 13-20.

[11]R.H.Coase,"The Nature of the Firm," Economica, Vol.4, No.16,1937, pp.386-405.

[12] Oliver E. Williamson. Governance mechanism. Beijing: China Machine Press, 2016,pp.36-53.

[13] Williamson, O. (1973). Market and hierarchies. New York: Free Press.

[14] Zhang, W. Paradigm of transaction costs, Social science front, No1, 1999,pp.1-9.

[15] Zhang, J. Political sociology and its main research directions. Sociological research, No.03, 1998 ,pp.17-25.

[16] Zhang, J. Research on community led marketoriented ecological compensation mechanism -Based on the perspective of "system patching" and "resource patching", Journal of public management, No.3,2020,pp.1.

[17][Liu,W. Re-examination of China's social selforganization from the perspective of national governance. Learning and practice, No.4, 2015,pp. 74-81.

[18]Coleman, J.S. Foundations of social thery. Cambridge: The belknap press, 1990.

[19]Putnam,R.D. Making Democroacy work: Civic traditions in modern Italy. Princeton, $\mathrm{N}$. J. :Princeton University Press. 1994.

[20]Commission on Global Governance, Our Global Neighbourhood. Oxford:OxfordUniversity Press , 1995,pp.23,38.

[21] Xia, Z. Analysis on the functional coupling mechanism of multiple subjects in public crisis management. China Administration, No.5,2009,pp.122-125.

\section{Sources of funding for research} presented in a scientific article or scientific article itself

This research was support by following funds, which we are thankful for. In addition, the authors take all the responsibility for this paper.

(1) Department of Education of Guangdong Province "Innovative projects with characteristics of ordinary universities" project: Research on improving the quality of College Students' volunteer service (Project Number: 2017QWNCX211)

(2) The 13th five-year plan for the development of Philosophy and Social Sciences in Guangzhou project: From freedom to consciousness: A study on the construction of volunteer culture in Guangzhou (Project Number: 2019GZGJ211)

Creative Commons Attribution License 4.0 (Attribution 4.0 International, CC BY 4.0)

This article is published under the terms of the Creative Commons Attribution License 4.0

https://creativecommons.org/licenses/by/4.0/deed.en_US 